\title{
Considering the Human Element of Long-Term IT Outsourcing: A Case Study of an Australian Bank
}

\author{
Frank Gutierrez and Laurel Evelyn Dyson \\ Centre for Human Centered Technology Design Research, \\ University of Technology, Sydney, Australia
}

\begin{abstract}
While many studies on outsourcing have identified its advantages and disadvantages from an organizational perspective, there has been insufficient attention paid to the impact of outsourcing on employees.

A case study methodology was used in the analysis of the effects of IT outsourcing on the wellbeing of IT professionals working in a leading Australian bank. Despite the success of the outsourcing initiative for the organization, evidence from an intranet forum established in the six months prior to the outsourcing transition and surveys conducted of remaining staff two years post-implementation revealed a high degree of non-acceptance by both sets of workers. This arose despite management's attempts to communicate effectively with staff. Within this same period, the bank also had to adjust to the effects of a new psychological contract to which the now outsourced IT staff were working. The study concludes that the disaffection of staff resulted mainly from a lack of consultation during decision-making steps and a sense of powerlessness to influence management. Suggestions are provided as to how outsourcing could be accomplished in ways that improve employee acceptance and reactions to change.
\end{abstract}

Keywords: Outsourcing, managing organizational change, psychological contract, employee perceptions

\section{Introduction}

Outsourcing is not new. It can be traced back to eighteenth century England (Kakabadse and Kakabadse, 2000) and there are numerous industry sectors that have relied on outsourcing for decades. For example, many service organizations depend on their employees and the skills they have as their marketable commodity. When such organizations have requirements they are not equipped to handle, they "send it out."

There are very few decisions that have a greater ability to immediately affect every operational aspect of an organization (Corbett, 2003). Outsourcing has the potential to change processes, technologies, financial statements, customer relationships, suppliers, shareholders and employees. In particular, major organizational changes such as this affect people. The restructure resulting from outsourcing can be a frightening experience for those who, by nature, are resistant to change.

In order to explore the impact of outsourcing on the people working in an organization, the authors undertook a study of an Australian bank - called here OzBank which was in the process of outsourcing their Information Technology

Copyright (C 2010. Frank Gutierrez and Laurel Evelyn Dyson. This is an open access article distributed under the Creative Commons Attribution License unported 3.0, which permits unrestricted use, distribution, and reproduction in any medium, provided that original work is properly cited. Contact author: Frank Gutierrez, e-mail: Frank.J.Gutierrez@student.uts.edu.au 
Operations division to an organization referred to here as Bower IT. This decadelong, AUD4.3 billion dollar undertaking would directly affect nearly 1,000 employees. It is important to note that a condition set by each party in the outsourcing agreement (OzBank and Bower IT) was that a certain level of acceptance of the decision to outsource had to be achieved by affected employees prior to the contract becoming active. Thus managing the feelings and the reactions of people was of paramount importance to the success of the project.

In focusing on the people issues we will ascertain whether 0zBank's decisions were made with the best interests of their employees in mind. Coincidentally, the executive committee had been heavily promoting the future directions of the bank as the leading Australia and New Zealand banking company and the "employer of choice" (OzBank Internal). The result of our focus will allow us to determine recommendations for greater buy-in from affected employees than OzBank managed to achieve in this case.

The material for this study derives from detailed information provided by a member of the OzBank team managing the outsourcing contract as well as surveys of IT operations staff working at the bank and affected by the decision to outsource. In addition, the researchers were provided with transcripts of comments made by IT employees on an intranet forum established by the organization to allow staff to express their views and ask questions. These transcripts included senior management's responses.

\section{Business Drivers for Outsourcing at OzBank}

From an organizational perspective, the main driver was to achieve increased shareholder value. This driver permeated all business units at the bank. Most companies considering outsourcing see it as leading to lower costs (Seo and La Paz, 2008; Haag and Cummins, 2008). One reason for this is perceived economies of scale, whereby costs are lower for specialist companies that deal in higher volumes of products than their non-specialist counterparts (Thompson Jr. et al, 2008). By this reasoning, Bower IT would presumably be able to provide the same IT operations that internal OzBank staff provided, but at a lower cost. Ultimately the bank was changing focus and moving towards a "core" business model concentrated on banking. The concept of "Core Vs Context" is often used in outsourcing discussions. Moore (2009) explains that "whatever defines you, whatever gives you the competitive edge is core while everything else is context". A refocus on core business accounts for 32\% of organizations adopting outsourcing (Corbett, 2003). Outsourcing non-core areas, which usually produce no revenue, allows the organization to concentrate on their core profit-generating business (Haag and Cummings, 2008). In OzBank's case, the employees whose expertise was considered core were retained, but the IT staff were considered "in-scope" for the outsourcing project and were targeted to transition to the partner organization.

Additionally there was some external pressure on the bank to increase performance relative to the market sector. Competitors were entering into, or had already entered into, IT outsourcing agreements and had begun to realize the benefits while OzBank appeared to lag by maintaining its IT in-house.

Interestingly, the decision to outsource was announced in the first quarter of 2000. As part of the massive body of work undertaken during the Year 2000 project to convert the year fields in the bank's databases, applications and other technical infrastructure from a 2-digit to a 4-digit format, the databases recording all ITrelated equipment, software and assets had also been brought up to date and an accurate snapshot of these components recorded. OzBank was thus able to provide this detailed information to the prospective outsourcing provider as a precise view of the state of their IT operations. The question of how and what to transition to the outsourcing provider was made significantly easier by being able to identify these discrete components in the first instance.

\section{Employee Expectations}

Against the background of a successful and recently concluded IT Year 2000 project, IT staff at OzBank were basking in a sense of being appreciated and valued by senior 
management for their efforts. Despite the sensational stories of possible Year 2000 disasters that had gained currency in the media, the New Year was received with no reported IT problems for OzBank. This project had been as unpopular and inconvenient as it was seen as compulsory for the organization, and yet workers had willingly committed longer hours in order to achieve its immovable deadline.

Consequently, IT staff felt outraged and betrayed to learn that their employer was planning to outsource IT operations. The majority of IT staff at OzBank did not want to be outsourced, and they certainly did not want to work for any of the short-listed potential outsourcing partners. Understandably, OzBank IT staff expected to be given clear business reasons for the pending outsourcing exercise, as demonstrated by this excerpt from an intranet forum designed to facilitate communication between management and IT staff:

Simple question - if the decision is such a good one, why won't senior management give us the justifications/reasons in clear and unambiguous terms? Tell us the savings $\$ \$ \$$ that we're going to make. Tell us where we'll be saving money. Tell us what "leverage of a technology partner" actually means, and how/why we can't do it at present... Give us the facts, not platitudes.

While senior management did respond to such queries via the forum, they were also concurrently quoted in the media as saying that they wanted to be relieved of the "mundane and boring" that came with operating IT in-house. Thus public comments such as this made OzBank staff believe that they were indeed being given the "platitudes" that they despised.

Not surprisingly then, senior management's responses were not always accepted or respected. However, of note was that some of their answers belied an inconsistency with regards the contingency planning and forethought that they had themselves previously imposed upon IT staff. The response to an employee's question, "So is there a Plan B?" was staggering for many: Senior management replied to the effect that there would be no alternative plan in the event of the total failure of the outsourcing exercise, because they were not "going into this to fail." Thus while senior management may have been satisfied that they were responding to forum queries, IT staff were most unhappy at both the nature of the responses and the apparent ease with which they discarded critically important planning principles when it seemed convenient. Employees had previously held an expectation that OzBank would acknowledge their years of toil and effort. Instead, they were beginning to develop a sense of the magnitude with which the bank considered them to be dispensable.

\section{The Transition Process}

Following OzBank's decision to outsource, a tender document was issued and an IT service provider, Bower IT, was selected. OzBank recruited an outsourcing specialist to manage the initiative as the change agent. Being external, this position would protect the project director within the company from any ill feeling.

The outsourcing announcement was made six months prior to the transition date. From the bank's perspective there was an element of risk in the timing of the outsourcing disclosure. The bank needed to ensure that the intellectual capital was retained and that in-scope employees transitioned across to ensure business continuity. With more notice, the employees would have had more time to contemplate leaving the organization. A longer timeframe could also have seen the employee's morale suffer and affect productivity and co-operation in capturing important tasks and procedures.

\section{Transition of Non-Staff Components}

The mainframes, minicomputers and telecommunications equipment owned by OzBank were sold to Bower IT, generating a one-time cash influx for the bank. Bower IT also took over the lessee responsibilities for all PC-based servers, desktop computers and laptops which OzBank had been leasing from a specialist PC leasing company. However, in a shrewd move, OzBank placed the responsibility of transitioning almost all other non-personnel issues to Bower. OzBank identified these components and issues, stating that they would become Bower IT's legal responsibility from day one of the contract, and divested itself of any more involvement. Because of this, what 
had previously been depreciated assets became operational overheads. In addition, the agreement stipulated that the partner had to provide increases in not only capability but also processing power, functionality and capacity, therefore putting the onus on the partner to develop the necessary skills and or capacity to meet the bank's future requirements.

\section{Staff Transition}

More than $95 \%$ of OzBank IT staff accepted a guaranteed offer of employment by the outsourcing provider. The successful transitioning of most IT staff from OzBank to the provider meant that two serious risk factors from the client side were avoided (Cheong Cheng, 1996). The IT employees already had the trust of OzBank users, having worked alongside them before, and they had detailed knowledge of OzBank's systems. In order to entice affected staff to take up the offer, OzBank proposed to pay staff a gratuity for transitioning, in addition to retaining any accrued benefits deriving from their length of service. At first, employees who refused were not to be given either the gratuity or any redundancy payout. OzBank considered that if the employee chose not to accept, they were in effect resigning, as they were offering continued employment for all in-scope employees. In representing the affected OzBank IT staff, the Financial Sector Union (FSU), sought a ruling from the Australian Industrial Relations Commission (AIRC). The AIRC ruled that OzBank would be obliged to pay redundancy to those staff who declined their offer of employment with the new company, but that it would be reduced to $50 \%$ of the full rate. This reduction was due to the reasonable certainty of employees being offered jobs with the new company. That OzBank did not contest this ruling showed that it was prepared to satisfy the minimum legal requirements as set out by relevant authorities.

On the day before the outsourcing agreement came into being, the affected IT staff went home as employees of the bank. Arriving at their desks the very next working day, they would be considered employees of the new outsourcing partner, Bower IT. However, they would still be working in the same roles - these personnel would remain doing the same types of tasks that they had been doing on the previous working day. The project leaders from both companies had decided that on Day One of the outsourcing agreement, ostensibly nothing would be different apart from approximately 1000 former OzBank IT workers now being employed by Bower IT.

\section{Managing Staff Reactions}

Management at OzBank made considerable efforts to communicate interactively with affected staff. This was initially done via a series of in-person forums at which the change agent explained the rationale behind the decision to outsource and the projected timeframe, as well as fielding questions from staff. Additionally, marketing-style exercises were conducted by the potential outsourcing partners, who tried to sell the idea of working for an IT-focused company. Counseling was also provided to staff. Most of this had minimal effect.

Immediately after the initial announcement by the bank of its intention to outsource IT operations, management provided an intranet-based forum whereby all affected staff could interact with the change agent himself as well as with the senior managers that were driving the project. The intranet discussion site enabled staff to pose questions and the project team aimed to respond to each of them within four working days. However, with around one thousand affected employees, this was a commitment that was not always achieved. The project team also informed all staff of important project dates via a timeline chart that was available at the same intranet site.

Senior-level managers who were in charge of areas in-scope for being outsourced held official team briefings to pass on updates that they had been given by upper management. At these briefings, the senior managers would often state the factual components of the update, after which they would give their somewhat restrained personal position on the developments.

Finally, a forum was arranged between the IT workers and the executive team that reported directly to the CEO. It was at this meeting that staff finally realized that they were no longer wanted nor needed by the bank. Executives who fielded questions were verbally aggressive and feisty in their responses to genuine questions from 
workers. Affected IT staff finally realized that they, indeed, had very little power in preventing this exercise from being completed. Although a lot of effort had gone into creating open communication flow between management and employees what actually occurred was an opportunity to air opinions and grievances, but there was little chance of altering the decision. From Carnall (2007), we see that the OzBank management adopted the open-door control model, whereby employees were allowed to air their views but on a relatively narrow agenda. Once the executive had committed to the plan and engaged the outsourcing partner, they adopted a top down, powercoercive approach to the deployment (Cheong Cheng, 1996).

\section{Reactions to the Change by Employees}

The human element in the transition will be the hardest part in the outsourcing process. (Ovitz Taylor Gates, 2003)

The consensus from employees we spoke with was that the six-month notice given by the bank was too short. Greaver (1999) notes that a goal of communicating outsourcing arrangements to staff is to avoid unnecessary shocks as the project progresses. Unfortunately, this was not achieved at OzBank, because IT staff had generally thought that their previously successful efforts and congratulations on completion of their Year 2000 compliance duties meant that they were, indeed, an important part of the bank's staff population. That is, regardless of efforts at communication made by management, affected personnel generally were in shock for several months. Communication had begun far too late. As Garvin and Roberto (2005) point out, an effective campaign of persuasion must commence well before the announcement of any major changes, not afterwards, as OzBank had done.

The feelings of employees centered not so much on surprise at the announcement that IT would be outsourced, but rather on the lack of previous consultation and the fact that they had been given very little indication that it was part of the bank's plans. Workers felt that an implicit social contract between the bank and the employee had been broken. The result was that the employees were now suffering from uncertainty, anger, depression, guilt and betrayal. Subsequently, absenteeism and a lack of commitment became common. Elsewhere, Kakabadse and Kakabadse (2000) refer to this occurrence as "decreased management credibility" or survivors' syndrome.

The IT employees, who had generally had a great deal of pride in their work, were also concerned at what they saw as decreasing levels of support for the people they were servicing in OzBank:

Since my company's outsourcing of its
technical support unit, I have noticed a
significant decline in quality of support
and service response times. There is no
doubt that employees of other companies
do not have the same drivers and
motivation as same company employees
especially ... where the workforce is so
transient.

However, I can appreciate the view that alignment to a large IT organisation should provide skills and expertise in major projects at the macro level. It's really only at the micro level, where people actually have to work with the systems developed, that outsourcing has real shortcomings.

By surveying the IT employees two years after the transition, we were able to determine their long-term perspectives and reactions. Interestingly, some still entertained negative sentiments such a length of time after the initial transition had been completed. There were four main classes of response to the proposed outsourcing operation:

\section{Strong and Vocal Disapproval}

Most OzBank staff that were in-scope for being outsourced had been quite happy working for the company. Thus, they were deeply disappointed and felt betrayed that upper management could treat them as unwanted ballast, especially after the immense effort they had made for the recently completed Year 2000 project. This was clearly expressed via intranet discussion sites:

IT has already been effectively told that we're not good enough. Morale has plummeted, as has loyalty. This process has been aided and abetted by the fact 
that many have slogged their guts out for this company over the past few years ... and this is our apparent reward. Taciturn Disapproval

Some staff members chose not to be vocal about the proposed outsourcing arrangement, but would privately confide that they did not agree with it.

\section{Disapproval yet Acceptance}

One of the smallest groups consisted of those who did not agree with the proposed organizational change, but believed that because upper management had decided upon this course of action, there was little that they could do to affect the outcome. Some of these staff members had even begun using the intranet discussion site to advise their colleagues to stop complaining about the proposed outsourcing operation; they believed that nothing could be done to alter what they had come to view as a fait accompli.

\section{Depression and Other Psychological Reactions}

Several staff members were reported to have become depressed or exceedingly angry due to the whole situation. One staff member even posted what could have been construed as a veiled threat to carry out a violent act, but it was quickly removed from the intranet forum and an apology was given.

\section{Review of Organizational Change at OzBank from Various Perspectives}

Outsourcing often generates fear and resistance among employees and so the overall result can depend on how well it has been planned and how positively and truthfully the changes are communicated. As Haxton (1988) contends, discussions of pain and gain are political. Perceptions differ between different stakeholders such as employees, outsourcers, service provider and customers. Despite the negatives there are usually some genuine benefits. So did the bank do the right thing by the employee?

Employee Pains
The OzBank incumbents who had their roles outsourced to Bower IT were not given any power to determine whether the outsourcing exercise occurred or not. The change was forced upon the OzBank IT staff. The notification period was only six months, a relatively short period of time to make an important decision about one's future. The bank broke its implicit social contract with the employee. Breaking such a contract commonly leads to a drop in morale and distrust (Kakabadse and Kakabadse, 2000).

In addition to these concerns was the fact that Bower IT had the freedom to move any of the in-scope employees onto contracts other than OzBank as part of the terms and conditions of their continued employment. Moreover, they had only guaranteed employment for 12 months with Bower IT following the transition. Though private companies do not exist primarily as benefactors for their employees, how can the outsourcing organization express credible confidence about affected employees' futures when they have little control once the employees have transferred to the IT service provider?

Finally, OzBank was not prepared to pay full redundancy or long-service leave entitlements for those staff who declined the offer of employment, although it was forced to pay $50 \%$ redundancy by the IRC.

The bank's approach during the years preceding its outsourcing decision could be said to have focused on the strengthening of organizational capabilities by a more participative style of leadership aimed at developing the culture of the organization. This was a change management approach typified by Beer and Nohria's "Theory 0 " (2000). However, with the arrival of the new CEO, there seemed to be a new emphasis on the maximization of economic returns, a top-down leadership style and a focus on restructuring the organization through outsourcing, which was more congruous with Beer and Nohria's “Theory E" (2000). As a result, staff felt betrayed and there was a sense of mistrust and personal distancing from the company. Any idealistic illusion that OzBank was the employer of choice and a fantastic Australian company to work for had been removed. This is, indeed, one of the criticisms that may be directed toward outsourcing - employees suffer low morale and motivation when they 
realize that their employer is only their benefactor as long as it serves the company's goals.

The researchers, who tried to view the situation objectively, could see that the bank's top managers were making difficult decisions. By not appealing against the AIRC's ruling in favor of employees who chose not to be outsourced to the other company, the bank was indicating that it was intent on satisfying its legal obligations towards its staff. However, it did not suggest that it was interested in doing any more than the absolute minimum. For a publicly listed company, the bank's top management was naturally focused on increasing shareholder value, which was what the outsourcing intervention was meant to achieve.

\section{Employee Gains}

Looking at the reverse side of the issue, the outsourcing and transition to Bower IT did provide a number of positives for the inscope employees. OzBank negotiated for former staff who accepted the offer of employment with Bower to receive a onetime gratuity calculated on their years of service with the bank. OzBank also ensured that accumulated length of service would be carried through to the new employer. Thus, an employee with ten years' service would transition to Bower as though they were a ten-year employee, with the benefits (for example, long service leave) that went with it. While not immediately obvious for staff, IT professionals moving into an organization such as Bower IT had potentially wider opportunities for development and growth.

\section{OzBank Pains}

It is worth remembering that the majority of in-scope IT staff at OzBank did not want to be outsourced, and they certainly did not want to work for Bower IT. OzBank IT staff had taken pride in their work and felt pride in being associated with the bank. By contrast, most had viewed Bower IT employees with disdain, as though they were indeed the bowed and vanquished survivors of past outsourcing events.

However, even during the days of in-house IT operations at OzBank, the IT security division had not been easy to work alongside. While other IT divisions had seemed to have a 'can-do' attitude towards enabling business initiatives, the security division rightly saw its role as being one of control, in order to maintain its protection of the bank's sizeable capital and information resources that were accessible online. Understandably, being outsourced to an organization they did not aspire to work for did not make them any easier to work with (Deare, 2006).

In 2006, the bank's Chief Information Security Officer (CISO) was quoted in an IT periodical as saying that this had caused problems with both receiving technical support and IT delivery. (Tung, 2009). The CISO admitted that it had been a mistake to outsource security to Bower IT. It had also become apparent that the outsourced security personnel were now working very closely to the requirements of the services contract, which in itself did not provide the security staff with adequate understanding of the initiatives that the bank was subsequently trying to accomplish

Moreover, the bank had come to realize that it had lost control of various parts of its business with regards IT services delivery, and that these had begun to have an effect on the workings of the organization. As a solution, the CISO formed a new bank-side team as a counterpart to the Bower IT security team, with clearly defined roles and responsibilities - the OzBank team would be responsible for the development of policies that reflected the needs of the bank, while the Bower IT security group would provide the required services (Deare, 2006).

\section{Breach of Psychological Contract}

Much of the shock, misalignment of expectations and unhappiness experienced by the affected staff of OzBank and Bower IT can be explained via the concept of psychological contract, and the consequences of it having being broken (Ang and Slaughter, 1998).

Similar in some respects to social contract, psychological contract "represents individual's beliefs and expectations about the terms and conditions of their reciprocal relationships with their employers." (Ang and Slaughter, 1998). Ang and Slaughter (1998) note that contracted or outsourced workers view their responsibilities as more 
"transactional" and less "relational" than permanent employees. Thus outsourced workers may perform their tasks more from an official obligation rather than due to an intrinsic desire to help the company achieve its goals.

However, it is this relational responsibility that IT staff had felt while working for OzBank, of which the bank had been an ongoing beneficiary. Prior to the outsourcing transition, employees had often willingly sacrificed personal time by working long into the evening or the weekend in order to guarantee the success of various projects. This was not just work for payment. It was genuine engagement involving a very personal commitment to help ensure the success of the organization. In turn, the bank appeared to be as benevolent and appreciative as a profitdriven organization could seem to be. Of course this notion was annihilated the instant that the bank announced its intentions to outsource IT and thus relieve itself of what it had begun to refer to as the excess ballast or dross that was in-house IT. This was the first step in the bank dishonoring an implied psychological contract.

Accordingly, when the bank tried to enlist the assistance of previously in-house IT security staff in projects, there was a mismatch in expectations. As a minimum, OzBank may have expected the security staff to exhibit the same previous level of dedication towards the tasks at hand, thereby assuming the validity of the original psychological contract. In contrast, the nowoutsourced security staff viewed their duties to OzBank in a more transactional way, indeed giving precedence to the official contract for services as a guide to their actions and level of commitment over any previous psychological one.

In this way, organizations need to understand that while the same personnel may yet provide services after they have been outsourced, their very nature in terms of how they perceive and perform their work can be very different. This then has the potential to affect the outsourcing venture and in turn the whole corporation.

Perhaps mitigating this potentially disastrous situation was that the halfway point of the ten-year contract was looming. As per the contract, OzBank had the choice of exiting the outsourcing agreement after five years if it was deemed to no longer be appropriate. This would have set the scene for an interesting interplay between the contractual obligations of Bower IT security staff and the psychological contract that they would have been working to under their subsequent employers.

In the last quarter of the ten-year contract, the former $\mathrm{CIO}$, and the outsourcing specialist who drove the change were sought for comment on how they had come to view the success of the original exercise (Gedda, 2007). The former CIO remained firm that it had been the right course of action, yet added that the current trend was to have smaller "multisourcing" agreements instead of a single large one. This was thus an indication of an increased level of sophistication regarding skills in managing outsourcing relationships. However, the outsourcing specialist was more wary in his assessment. He stated that due to negative perceptions of how the outsourced IT services were provided to OzBank, he would no longer support such long-term arrangements. This may in part be explained as a consequence of breaching psychological contract. He also indicated that ten years was perhaps too long a period in which to maintain enthusiasm for such an undertaking (Gedda, 2007).

\section{Conclusion}

To answer the question "Were the bank's decisions made with the best interests of their employees in mind?" we must consider two perspectives: those of the bank and of the employee.

From the bank's perspective, what is apparent is that the strategy was to improve shareholder value first and foremost. Morgan Chambers (2003) argue that outsourcing initiatives have a positive impact on the share price. Outsourcing deals are generally welcomed by the share market as a good indicator that companies are on their way to cost cutting and increasing the bottom line. Certainly, OzBank's decision to outsource led to at least short-term monetary gains through the sale of its IT and telecommunications equipment. Whether long-term cost saving was achieved or otherwise is another question and beyond the scope of the current study to determine. However, Windrum, 
Reinstaller and Bull (2008) note that short term gains are rarely sustained in the long run, with companies that engage in outsourcing suffering low productivity growth. This occurs because the scope for continuing innovation with respect to the outsourced activity is severely limited as the organization no longer has control over it. OzBank's IT staff saw it very much as a short-term exercise. For example, one contributor to the intranet forums pointed out that major projects were no longer being approved following outsourcing because of the monthly maintenance fee levied against any new system, over and above the cost of systems development. Moreover, they questioned the ability of OzBank to maintain its competitive lead in the long term:

Yes we can buy leading edge technology products and services from these companies but they will also be selling them to our competitors ... where is the competitive advantage?

The second aim of the bank was to retain intellectual property through transitioning in-scope employees to the outsource provider. With $95 \%$ of IT employees successfully transitioning, it would appear that the outsourcing initiative was successful from the bank's point of view on this criterion. People are the most important asset of an organization. The bank recognized the main risk of the project was in retaining valued employees as they were crucial in guaranteeing continuation of business from day one. Without the vast majority of employees accepting the offer, the project could not have gone ahead. The initiative was successful from a short-term business perspective as the outsourcing did occur and Bower is now providing IT services to the bank.

From an employee point of view, the success of the outsourcing initiative was less straightforward. Even if the bank did not make its decisions with the employee in mind, it did put in place strategies to ensure continued employment and retention of accrued employment benefits. In addition, the communication channels, counseling services and cash incentives all worked to the benefit of the employees, even if the motivation was largely one of ensuring successful transition. However, from a people perspective, the bank merely did the minimum required in order to achieve the acceptance figures and to cover their legal obligations. The employees had no real option but to transition. The bank took everything away from the employee: their job, their trust and their pride in the work they had done for OzBank. Culturally there was a major personal impact for the transitioned staff and moving to Bower IT was not their preferred option. The bank exploited the loyalty of its most valuable asset resulting in negative sentiment appearing in the surveys conducted by the researchers even two years after the fact.

Outsourcing employees can also breach existing beneficial arrangements such as psychological contract. When employees perceive that this has not been honored, their morale and loyalty suffer. Complicating matters further is that the outsourced employee may naturally begin to develop a psychological allegiance with their new employer. This may result in the unusual situation of the same person providing a service, providing it in a less engaged and very transactional manner.

As a result of our study, and in particular the pain that the outsourcing initiative caused OzBank's employees, there are some general recommendations that we are able to make:

- Allow the internal IT department to review its cost/revenue model. There may be some opportunities for the IT department to become a profit centre rather than a cost centre. For example, one employee noted that OzBank:

...has 30 plus years of running IT Shops and distributed networking (Branches, ATM's etc) [sic.]. We should be leveraging off this experience, and selling our well established, managed \& reliable services to other organisations and companies and MAKING money.

By moving to a profit centre, the IT department could be compared directly with external providers when decisions are made whether to outsource or not. This could also mitigate the supposedly higher costs that in-house IT operations incur as compared to the scale economies enjoyed by specialist outsourcing organizations. 
- Allow internal IT to respond to the tender document. It is rare that the IT department ever have the opportunity to respond.

- Investigate shared service models in which the IT department and a potential service vendor work together. This may provide a lower cost approach to outsourcing.

- Engage in partnerships with external vendors involving a phased approach to the transition process and co-location of employees. In this model, some functions can be outsourced and the employee would relocate to the service provider's location while still an OzBank employee. The perception would be that these employees would be the subject matter experts, transferring knowledge to the vendor. The employee would remain satisfied as an OzBank employee while becoming used to the vendor environment and culture. As more functions were outsourced the change would have less impact and at the same time reduce the risk of employees leaving.

- Better prepare the in-scope employees for the change. This focus should centre around the advantages to the employee, particularly the career development opportunities and the opportunity for the individual to join an IT business culture.

- Understand the effects of a change in psychological contract and be prepared for how outsourced employees may subsequently view their obligations in a different manner.

- Consider multisourcing as an alternative to long-term contracts with a single provider.

Ultimately, outsourcing is often feared among the IT ranks. Why? Organizations are more concerned with shareholder value and the success of the project than the very people who give so much of their life to keep the organization in business. Outsourcing could be viewed with much less skepticism if some of the recommendations we have made were adopted. Changing roles does not have to be such a harrowing experience and can even lead to better work opportunities.

\section{Acknowledgement}

The authors would like to thank Rehan Alavi, Raj Krishnappa and Craig Secombe for their assistance with this study. Additionally, the guidance and encouragement of David Paul were much appreciated.

\section{References}

Ang, S and Slaughter, S. (1998), 'Organizational Psychology and Performance in IS Employment Outsourcing and Insourcing,' Proceedings of the $31^{\text {st }}$ Annual Hawaii International Conference on System Sciences (6), ISBN: 0-8186-8255, 69 January 1998, 635-643.

Beer, M. and Nohria, N. (2000), 'Resolving the Tension between Theories $\mathrm{E}$ and $\mathrm{O}$ of Change,' Breaking the Code of Change, Beer, $\mathrm{M}$ and Nohria, N (eds), Boston, Harvard Business School Press.

Carnall, C. (2007) Managing Change in Organizations, $5^{\text {th }}$ ed., Prentice Hall, FT Press, UK.

Cheong Cheng, Y. (1996), School

Effectiveness and School-based

Management, Falmer Press, London.

Corbett, M.F., (2003), 'Outsourcing's Next

Wave' Corbett Associates. [Online],

[Retrieved 15 May 2003], http://www.corbettassociates.com/home/d efault.asp

Deare, S., (2006), 'Westpac CSO tells of 'battle' with IBM contract,' ZDNet Australia. [Online], [Retrieved October 13, 2009], http://www.zdnet.com.au/westpac-csotells-of-battle-with-ibm-contract139265315.htm

Garvin, D.A. and Roberto, M.A. (2005) 'Change Through Persuasion,' Harvard Business Review, 83(2), 104-112.

Gedda, R., (2007), 'Westpac's Outsourcing Architects Show True Colours,' Computerworld, [Online], [Retrieved 13 October, 2009],

http://www.computerworld.com.au/article /189987/westpac_outsourcing_architects_s how_true_colours / 
Greaver, M.F. II. (1999) Strategic Outsourcing, AMA Publications. New York.

Haag, S., and Cummings, M. (2008) Information Systems Essentials, $7^{\text {th }}$ ed., McGraw-Hill Irwin, New York.

Haxton, H.E. (1988) 'The Pain and Gain of Outsourcing,' Proceedings of the $15^{\text {th }}$ National Convention of the Records Management Association of Australia, September 1988.

Kakabadse, A and Kakabadse N. (2000)

'Critical Review - Outsourcing: a Paradigm Shift,' Journal of Management Development 19(8), 670-728.

Moore, G., (2003) 'The Age of Outsourcing,' CSC World. [Online], [Retrieved October 13, 2009],

http://www.csc.com/features/stories/122 65-

geoffrey_moore_on_the_age_of_outsourcing

Morgan Chambers., (2003), 'Outsourcing in the FTSE 100 - The Definitive Study:

Episode 2: Impact on Financial

Performance,' Morgan Chambers. [Online],

[Retrieved May 15, 2003],

http://www.cw360ms.com/outsourcing/in dex.asp

Ovitz Taylor Gates (2003). 'The IT

Outsourcing Essentials Guide,' Ovitz Taylor Gates [Online], [Retrieved May 15, 2003], http://www.ovitztaylorgates.com/TheITOu tsourcingEssentialsGuide.html

Seo, D. and La Paz, A.I. (2008), 'Exploring the Dark Side of IS in Achieving Organizational Agility,' Communications of the ACM 51(11), 136-139.

Taylor, H. (2005), 'The Move to Outsourced IT Projects: Key Risks from the Provider Perspective,' Proceedings of the Conference on Computer Personnel Research, 149-154.

Thompson Jr., A., Strickland III, A. and Gamble, J. Crafting \& Executing Strategy, $16^{\text {th }}$ ed., McGraw-Hill Irwin, NY, 2008.

Tung, L., (2009), 'Backley hangs up Westpac jersey,' ZDNet Australia. [Online], [Retrieved October 13, 2009],

http://www.zdnet.com.au/backley-hangsup-westpac-jersey-339295469.htm
Windrum, P., Reinstaller, A. and Bull, C. (2008), 'The Outsourcing Productivity Paradox: Total Outsourcing, Organisational Innovation, and Long Run Productivity Growth,' Journal of Evolutionary Economics 19(2), 197-229. 